\title{
Colonialidad/ \\ decolonialidad \\ de la conversación, \\ las referencias \\ y las citaciones
}

\section{Pedro Pablo Gómez}

Editor

Universidad Distrital Francisco José de Caldas

ppgmez@udistrital.edu.co

Cómo citar este artículo: Gómez, Pedro Pablo (2020).

Colonialidad/decolonialidad de la conversación, las referencias y las citaciones. Calle 14: revista de investigación en el campo del arte 15(27). pp. 10-13.

DOI: https://doi.org/10.14483/21450706.15435 


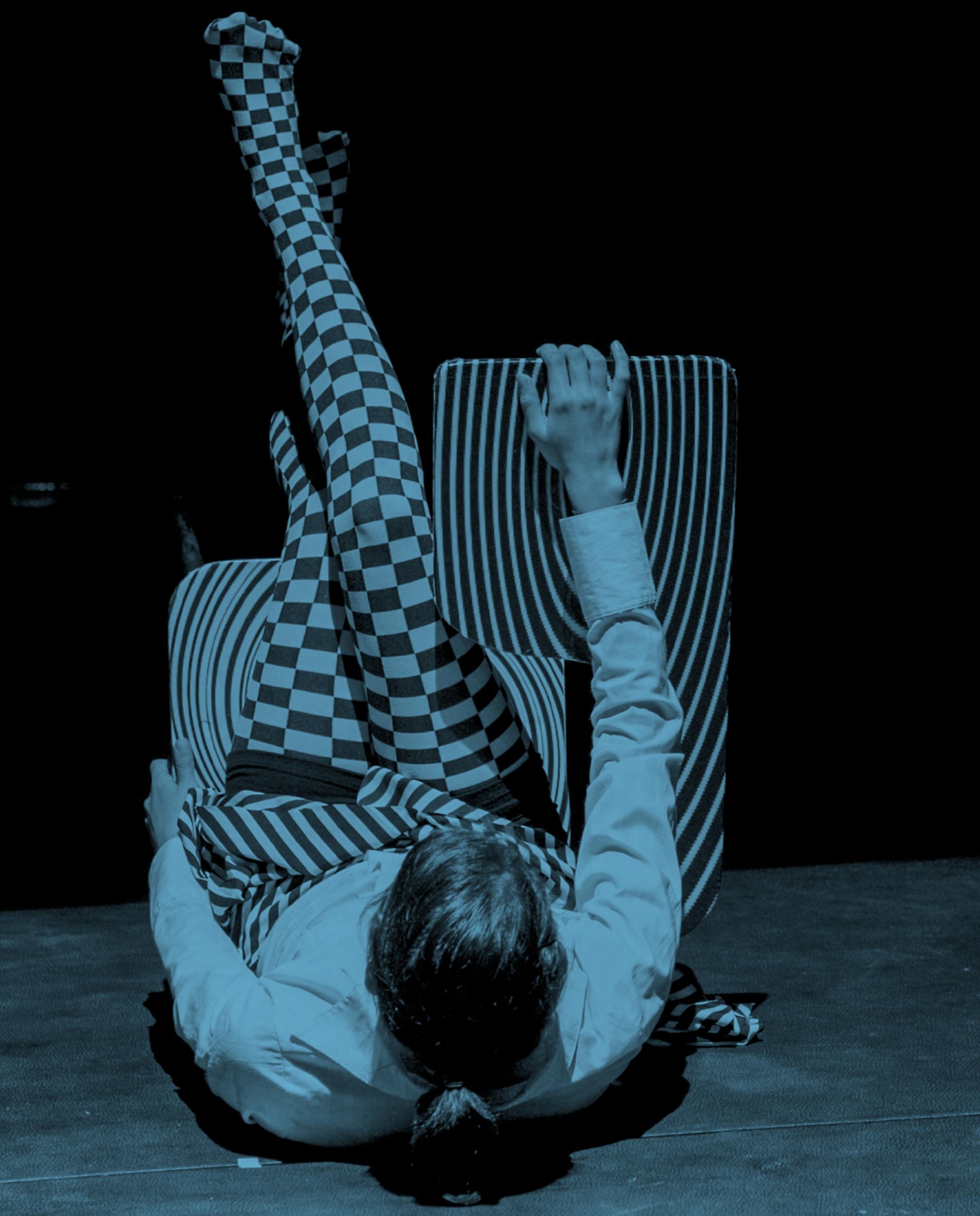


Como bien lo ha explicado el sociólogo peruano Aníbal Quijano, desde los inicios de la modernidad, en sus centros hegemónicos, fue elaborado un modo de producir conocimientos que da cuenta de las necesidades cognitivas del capitalismo. Ese modo de conocer, denominado racional, que por su origen y carácter es eurocéntrico, fue impuesto y admitido en el mundo capitalista como emblema de la modernidad y como la única forma válida de racionalidad. Esa modernidad/racionalidad se ha mantenido como perspectiva cognitiva del capitalismo colonial que naturaliza la experiencia de la gente dentro del patrón colonial de poder. Esto, a pesar de los respectivos cambios en los contenidos específicos (y no en los términos), en las críticas internas y debates en el transcurso del tiempo sobre la modernidad/colonial/capitalista/eurocéntrica. Claramente, esos cambios fueron necesarios por las exigencias cognitivas del capitalismo (primero comercial, luego industrial, post-industrial y neoliberal) en su relación con la naturaleza y su pretensión inacabada de objetivar como mercancía todos sus recursos, además del trabajo y sus divisiones.

El eurocentrismo, entonces, no es solo la perspectiva cognitiva de los europeos, sino del conjunto de todos aquellos que hemos sido educados bajo su hegemonía; es un conocimiento etnocéntrico, situado, que se universalizó como la perspectiva cognitiva de una historia local que fue capaz de imponerse como historia universal. En los listados de referencias de artículos, libros y demás producción académica, que se publican en revistas especializadas en un determinado campo del conocimiento, podemos darnos cuenta de la supervivencia del eurocentrismo. La mayoría de los autores referenciados son europeos o norteamericanos. Una minoría suele ser de autores latinoamericanos. Y mucho más abajo en el porcentaje aparecerán excepcionalmente autores asiáticos, africanos o autores locales o colegas de nuestras propias instituciones que indagan temas similares a los nuestros. Esto nos hace pensar en los términos de nuestras conversaciones, es decir, con quiénes queremos dialogar, y evidentemente la balanza se inclina hacia autores reconocidos sobre cuyos hombros queremos avanzar, como si fueran hombros de gigantes que caminan y nos llevan por la única ruta del conocimiento posible.

Lo mismo ocurre cuando a los artistas en formación, en nuestras academias de arte del Sur Global, se les pide contextualizar lo que hacen con los trabajos de artistas que sean sus referentes. En la mayoría de los casos, prefieren citar como sus referentes a artistas europeos o norteamericanos contemporáneos, cuyas obras sean reconocidas por la crítica de arte, publicitadas en revistas especializadas e incluidas en grandes exposiciones y ferias de arte internacional. Son muy pocos los que mencionan referentes latinoamericanos, nacionales o locales con quienes comparten problemáticas concretas en lo político, social, estético o cultural. Cuando esto último ocurre es porque los artistas locales han alcanzado reconocimiento internacional, muchas veces cediendo a las directrices formales y conceptuales del denominado estilo internacional, razón por la cual ahora sí pueden ser referenciados por los artistas jóvenes. 
Así como la mayoría de los autores que estudiamos, citamos y referenciamos en nuestras investigaciones son eurocéntricos, lo que hacemos no es otra cosa que aportar a la reproducción del eurocentrismo cognitivo, a mantener viva la matriz colonial del poder. Y al hacerlo, asumimos la paradójica situación del blanqueamiento epistémico y estético en la cual, tratando de producir conocimiento y arte siguiendo el canon de la cultura occidental y buscando ser aceptados en la categoría blanca de humanidad, lo que mejor logramos es mantener vivo el eurocentrismo y la vigencia de la matriz colonial del poder.

Esta matriz, como sabemos, junto con la idea de una racionalidad única, consolidó otro de los núcleos principales de la modernidad/racionalidad que tiene que ver con la concepción de humanidad según la cual la población mundial se diferencia, supuestamente por naturaleza, en inferiores/superiores, racionales/irracionales, primitivos/civilizados, tradicionales/modernos, insensibles/sensibles, mujer/hombre, objeto/sujeto, significante/significado, sur/norte, periferia/centro y una larga cadena de oposiciones en las que se justifica una clasificación social mediada por el racismo cognitivo, el sexismo, el generismo y el patriarcado blanco colonial.

Afortunadamente, hoy nos hemos dado cuenta de la trampa de la modernidad y de las lógicas que mantienen en funcionamiento la matriz colonial del poder. Pero este paso, importantísimo sin duda, no es suficiente. Nos queda la tarea de desprendernos, desengancharnos y apartarnos del patrón colonial del poder, si queremos salir de la modernidad/colonialidad, de la retórica progresista y de sus cantos de sirena que pretenden ocultar sus efectos destructores de la vida. Para tal fin, se hace necesario cambiar los términos mismos de la conversación, los aparatos formales y materiales de la enunciación (no solo los enunciados o los contenidos), poniendo a Occidente y su eurocentrismo en su lugar, como provincia geográfica y epistémica, como parte de un pluriverso intercultural, construido por aquellos que nunca tuvieron parte en la modernidad, pero que conservaron los conocimientos, saberes y memorias suficientes para enseñar(nos) rutas posibles para salir de la modernidad y de su lógica oscura y encubridora: la colonialidad.

Esos conocimientos otros de las víctimas de la modernidad/colonialidad, que el eurocentrismo chauvinista no pudo eliminar y borrar en quinientos años de violencias, des-humanización y exclusión, son los referentes que esperan ser citados para aportar a la creación del pluriverso posible, un pluriverso de razones y racionalidades en convivencia, en el que el Estado uninacional ceda el lugar a uno plurinacional, donde la uni-versidad eurocéntrica y disciplinar pueda transformarse en pluriversidad, donde el arte con A mayúscula, eurocéntrico y anestesia del sentir ocupe su pequeño lugar en el campo del hacer para que se abra tanto el mundo de los sentidos, como también los sentidos de los cuerpos hacia el mundo.

Desde Calle14 queremos aportar de manera efectiva al establecimiento de los términos no-coloniales de esa conversación. 